\title{
CREATIVE CULTURAL PRODUCT DESIGN IN THE BICULTURAL CONTEXT
}

\author{
Jong BOONPRACHA (1)* \\ Department of Industrial Design, Faculty of Industrial Technology, \\ Suan Sunandha Rajabhat University, Dusit, Bangkok 10300, Thailand
}

Received 26 January 2021; accepted 8 June 2021

\begin{abstract}
The study explores how to innovate creative cultural product design by integrating two explicit cultures' contexts. The study proposes a four-step approach for developing uniquely innovative cultural products under a bicultural context: 1) Identify cultural context, 2) Survey comparable features of two different cultures, 3) Compare the differences and similarities of two unique cultures, and 4) Negotiate the differences and integration. The case study represented in the demonstration is the critical factor of the proposed approach. The SCAMPER technic was applied to generate creative ideas. The results show that bicultural communication is an essential strategy for fostering design innovation. The SCAMPER technic application helps the study reach developing creative cultural product design in the bicultural context.
\end{abstract}

Keywords: bicultural context, biculturalism, creativity, cultural product, product design, SCAMPER.

\section{Introduction}

Several of research find that cultural diversity can cause a physiological effect in the acculturation of societal identities or divide group cohesion and reduce team activity. Other scholars stress biculturalism's positive effects, including enhancing organizational behavior and promoting creative expansion (Friedman \& Liu, 2009). People from various cultures possess different customs and thoughts; hence, biculturalism needs people's ability to diffuse between two cultural knowledge systems. It means that bicultural persons need to learn ways of understanding the ideologies and social norms of two cultures (Schwartz \& Unger, 2010). When two cultures communicate, there is an exchange of different information systems. Such variations invite new understanding and unfamiliar knowledge to the original culture, facilitating different cognition, which forms innovation. Ethnicity, race, gender, and other demographic diversity may revitalize group dynamics. Significantly, voicing different points of view in a team aids in promoting organizational creativity and achieve breakthroughs.

\footnotetext{
${ }^{\star}$ Corresponding author. E-mail: jong.bo@ssru.ac.th
} 
Bicultural encounters may improve creativity as distinct ideas help persons generate novel networks of knowledge and groundbreaking proposals (Chaiyajan, 2013).

Foreign cultures, as explained by various scholars, promote variant thoughts. New knowledge and thinking are developed when diverging ideas are accommodated and personalized. Therefore, clarifying the bicultural context in design and arts may help people find unconventional and creative ideas and models of artistic works and products. Making useful and outstanding things is the key to creativity. Innovative products should offer originality and portray their worth to society and individuals. Software, design, art, games, music, and movies are some of the products discussed in creative industries (Chen, 2018). This understanding inspires the study to demonstrate how designers develop innovative cultural product models and concepts by mixing different cultures' features and elements.

\section{Creativity in the bicultural context}

Creativity is displayed in human practices at various levels, from daily life to developed technological industries. It is a prime engineer for promoting social harmony, the scientific revolution, technological innovation, and sustainable human advancement. Creativity has been explained in multiple manners. However, the standard definition is that it is usually regarded as the capability of producing useful and novel idea creation (Brown, 2009).

Presently, unmatched importance is credited to creativity because of the adoption of innovation-oriented and policy-based national development techniques and highly urgent world issues, including terrorism and global warming. As the primary outcome of human culture and an enriching cultural tool, creativity's relation with culture is an intensely intimate one and a complex association. It is, in a sense, inherent to culture. According to Shao et al. (2019), culture is categorized as the "background", making creativity an "object", which is probably to be a novel "background" for forthcoming and emerging "creativity".

Bicultural persons vary in the extent to which their cultural identities are incorporated. For example, some individuals experience their American and Asian sides as conflicting among Asian-Americans, whereas others experience them as compatible. Previous studies on judgments conclude that this individual variation impacts how bicultural people respond to circumstances that signal their cultures. Asian-Americans possessing high bicultural identity integration (BII) incorporate standards of their cued culture. For instance, they typically demonstrate American judgments whenever in the circumstances cueing United States culture. Additionally, Asian-Americans having low BII work oppositely, conflicting against the sign, such as typically portraying Asian conclusions whenever in an American situation. Similarly, Asian-Americans with high assimilative reactions have increased novelty ideas in divergent cognition tasks, mostly when they signal their American culture (Morris, 2016).

Mok and Morris (2010) explain that studies on social judgment conclude that bicultural people can demonstrate the reaction tendencies linked with one of their cultures. Scholars also find that these people automatically shift between the two response styles based on circumstantial cues like culturally associated images and languages. However, not all bicultural individuals do this. Those with compatible and assimilated identities tend to react interactively to cultural signals. For example, they often make individualistic choices whenever they 
are in situations that characterize the American culture. Biculturalism with less incorporated and disputing identities reacts differently. For instance, they usually make collectivistic judgments whenever they represent American culture (Inkong, 2017).

Corporate studies find that groups produce more novel proposals to issues when guided by interactions based on the individualistic instead of collective norms. This idea that divergent cognition is linked to Western culture and individualism has been an extendedstanding foundation amongst organizational practitioners. Asian companies have attempted to promote original thinking by westernizing the work environment. For instance, during the 1980s, Toyota sought heightened creativity by replacing customary Japanese titles with unofficial Western address designs. However, because Asian companies are highly populated by workers identifying with both Eastern and Western cultures, most of whom have failed to blend or integrate the two identities, westernizing the workplaces can result in more complex impacts than the early times (Mok \& Morris, 2010).

Prior studies have stressed significant impacts like individualism to promote novelty and originality. However, their analysis shows that cultural primes may boost or reduce idea novelty based on BII levels of bicultural individuals. The outcomes showcase that Western cultural signals are instrumental in generating novel recommendations amongst AsianAmerican populations with highly compatible and assimilated identities (Morris, 2016). However, Asian cultural prompts induce these reactions among individuals with conflicting and less integrated identities. This paper proposes that people whose bicultural identities are incorporated may inhabit the part that the cultural sign invites comfortably, without pressure upon the other cultural identity (Rodgers \& Milton, 2011). People that feel dispute between their cultures, on the other hand, cannot impose one identity without placing stress on their second one. Therefore, this group resists complying with the cultural cues and, as a result, overcompensate. Opposing concepts, which are at first sentient, will probably become nonconscious and automized over time.

Consequently, emerging literature concerning second-cultural encounter distinguishes these outcomes as creative gains antecedent. Research finds that creativity tasks' performance is linked to residing in another nation and conforming to it. Several studies find innovative benefits when two cultures are simultaneously experienced or when the issue to be rectified concerns them. According to Chiu and Kwan (2010), evidence proposes that some strategies can be involved in benefits from being exposed to foreign cultures. This incorporates decreased associations' conventionality and access to expansive idea pools. Their literature shows the possibility of bicultural encounters to promote enduring benefits within creative virtuosity.

\section{Cultural product design}

In cultural product design, the objective of cultural recognition can be accomplished by consolidating users' traditional and aesthetic values (Moalosi et al., 2005). The encouragement is to understand what and how cultural basis and values can be harmonized in cultural product design (Albrecht et al., 2000). The fundamental target is to develop a comprehension of users' values and behaviors that can be transformed into practical, attractive visual 
design and design conceptions (Julier, 2000). “Technology is not a good transmitter unless it is culturally calibrated" (Kaplan, 2004). Thus, designers must discreet their target users' esthetic, anthropological, technological, and sociocultural factors (Gaver et al., 1999). Design is representative of change, and designers need to know how they can either threaten or encourage the native cultural structures of the society. It is prevalently products that cultural values are negotiated. Consequently, design is an effective medium of communication that indicates the values model within its concerns.

In terms of cultural product design, identities will never discontinue thoroughly, even in the international world. When products are exported, a glance into the cultural identity of their country's origination is embedded in them. Nonetheless, Zec (2002) predicates that with expanding globalization of markets and competition, there are increasing multicultural effects on national identities. This globalization leads to a more extensive commonality of viewpoint and lifestyle and, in some cases, individuality. It is perceived that this emerges whenever global trade points to a more considerable regularity of product culture. It is evident that as users encompass themselves with products, they shift their way of living. Whenever users habituate themselves with and use similar products, their lifestyles become almost identical (Zec, 2002). This suggests that cultural divergences seem to develop into less significant as users grow in the direction of a universal, global and uniform culture. However, Zec's assertions are not perpetual, as his assumption disregards users' cultural preferences and is largely misleading. Cultural dissimilarities are here to stay, and they will drive designers to adjust and to distinguish their products for different cultures (Evans et al., 1997). Regardless of how arduously people attempt, it is unimaginable for them to dispossess themselves of their own culture, for culture is the intermediary through which they communicate. The society of norms, values, believes and behaviors establish everyday life and users' culture (Whiteley, 1997). It could be argued that if values and standards diverge, designers have to make sure that the product properties and advantages are transformed to these values (Lin, 2007).

\section{Methodology}

The study adopted Chen (2018) principles of a four-step approach for developing unique creative cultural products under a bicultural context:

1. Identify the cultural context;

2. Survey comparable features of two different cultures;

3. Compare the differences and similarities of two unique cultures;

4. Negotiate the differences and integration.

Associating one culture with another sounds to be a neat strategy, but it entangles different innovation levels. The below uses practical examples to identify three levels of bicultural communication values:

- Level 1: External culture as the decoration. This is the most straightforward value to combine different cultures. In this case, trivial product modification could be made according to the characteristics of the target culture. For instance, a toy figure can be dressed in Thai silk for a Thai market but dressed in kimono in a Japanese market. 
The indication of external culture is regarded as the decoration of products to boost more cultural identity from target customers;

- Level 2: External culture as the skin. This value considers an external culture as one demonstration of the local products. "Chinese Portuguese styles" or "Westernized Chinese styles" relate to this category. For instance, Thai musical instruments to perform classical music in an orchestra;

- Level 3: Profound communication between two cultures. Products in this level supply a communication platform for two cultures. These products do not belong entirely to any culture, but they maintain both their original features. Two cultures are blended into an integrated compound for a novelty, such as a furniture upholstery from the use of the concept of a combination of color and pattern of Likay (Thai traditional dramatic performance) clothes with European curtains. The result is a colorful furniture upholstery pattern of the Likay clothes, but it looks as simple as the European curtain style.

The above three levels present how two different cultures can be associated, from simple to complicated philosophy. Values of level 1 and level 2 help designers create new visual styles and appearances of their works, while level 3 offers a possibility to discover innovative product concepts. The key at this point is communication. Cultural communication requires twosided, which means both two participators would instead learn knowledge from each other.

The study applied the SCAMPER technique for creative thinking and innovative cultural product design. SCAMPER (Eberle, 1996) was enhanced by developing Osborn's (1963) brainstorming guidance (value of "extensive ideation", the need for idea checklists and guidelines for solving problems creatively and approaching to stimulate creativity) and persuade them into an amplified ideation skill. SCAMPER is an acronym for the next set of varieties and conductions: S for "substitute", C for "combine", A for "adapt", M for "modify"/"magnify"/"minimize", P for "put" to other uses, E for "eliminate", and R for "reverse"/"rearrange". The technique suggests the user with a set of workable action practitioner categories to create ideas that may be used to adjust solutions to a design problem(s). For each practitioner category, a set of questions guides thought and ideas (replace, add, modify, transform, etc.). Serrat (2017) and Lockton (2013) suggest that the motivation comes from seeking to answer questions that redirect analogous search to figure out a problem. For instance, if a designer was asked to upgrade the holding/gripping of a mug, he may decide on $\mathrm{S}$, which could guide him to displace the handle. Then he will make progress to the prompting questions of substitute variation such as: How can be substituted? What other material be used instead? Different place? From there, he can trigger design ideas that surrogate the handle for a new holding utensil made of an additional material that would be located in a different location than the existing handle.

Design heuristics, embraced by the practitioner categories in SCAMPER, find their resolve because resemblance correlations may exist with metaphors restored through the practitioners (Daly et al., 2012). Schön (1983) argued that there are no completely new problems or that at least an assigned design problem may be correlated to other already resolved problems. Schön added that to find a solution, one can always search for homologous solved problems, use the outcomes, techniques, or experience to find the answer. He references mathematical problems, but identical arguments relate to familiar problem solving; there- 
fore, SCAMPER suggests an advance toward the problem solution by constructing previous outcomes, supplying a heuristic to explore for solutions. Furthermore, SCAMPER has demonstrated its productiveness in expanding creativity (Mijares-Colmenares et al., 1993).

\section{Result}

The case study of innovative cultural products based on cross-cultural communication in level 3 discussed here is Thai craft called Benjarong and Chinese principle called Benjathat. This case study combines Thai and China cultures and leads customers/users to learn about different cultures' artistry.

Benjarong means five colors, but most of the colors used on the Benjarong are from five to eight colors. The primary colors used for the Benjarong are red, yellow, white, black, green, or blue. Benjarong ware is produced in many types of utensils such as bowls, plates, jars, bowls, spoons, potty, teacups, and tableware sets, etc. Benjarong is a popular product from both Thai and foreigners because of the beauty and refinement of the color and pattern identities. The making of Benjarong has many essential benefits to the local area, namely the heritage of Thai art and culture, and is an occupation of high-class handicrafts.

Benjathat in Thai or the five-elements is one of the principles of Chinese wisdom. Chinese people believe that all things, whether concrete or abstract, can be divided into five elements (earth, gold, wood, fire, and water), with each element being have power characteristics. Colors can be classified into five elements: colors of the earth element are yellow, orange, and brown. Colors of gold elements are white, gold, and silver. Colors of wood elements are green (dark and light), colors of fire elements are red, magenta, and pink. Colors of water elements are blue and black. Besides, shapes also represent each element: the square representing the earth element, the circle representing the gold element, the semicircle representing the water element, the triangle represents the fire element, and the tall-shape rectangle representing the wood element. Furthermore, the five elements have many contexts and beliefs and are one of the feng shui principles.

The case study is driven by two essential questions: How can cultural products be applied in this case study? What alterations or development can be made if this biculturalism was brought to cultural product design? These questions are essential to designing novel patterns for innovative cultural products.

This study shows how SCAMPER can be applied in cultural product design. The design begins with comparing and integrating two cultures from two countries, as shown in Table 1, and The SCAMPER principle was applied as follows (Figure 1):

1. Substitute was the first principle applied by replacing the hand-painting pattern of Benjarong with the graphic black-white pattern;

2. Combine was the next principle. It combined the graphic black-white pattern with the five colors of the Benjathat, resulting in five designs with five colors representing five elements of Benjathat: water, wood, earth, fire, and gold;

3. The design experiment was performed by applying each principle of SCAMPER;

4. Finally, the appropriate experiment's pattern was selected to put on the products. 
Table 1. Analysis of core ideas in the bicultural context of Benjarong and Benjathat (source: created by author)

\begin{tabular}{|l|l|}
\hline \multicolumn{1}{|c|}{ Principle } & \multicolumn{1}{c|}{ Content } \\
\hline Identify the cultural context & $\begin{array}{l}\text { Benjarong: art and handicrafts in pottery types with a unique expression } \\
\text { that reflects the advanced craftsmanship with value and identity in the } \\
\text { hand-painting of colors and patterns on the porcelain. }\end{array}$ \\
\hline $\begin{array}{l}\text { Survey similar elements in } \\
\text { different cultures }\end{array}$ & $\begin{array}{l}\text { Benjathat: Chinese wisdom in all things, whether concrete or abstract, } \\
\text { that can be divided into five elements (earth, gold, wood, fire, and water). }\end{array}$ \\
\hline $\begin{array}{l}\text { Compare the similarities and } \\
\text { differences }\end{array}$ & $\begin{array}{l}\text { Similarities: five colors and five elements. } \\
\text { Differences: handicrafts and wisdom. }\end{array}$ \\
\hline $\begin{array}{l}\text { Negotiate the differences and } \\
\text { integration }\end{array}$ & $\begin{array}{l}\text { Benjarong: a pattern. } \\
\text { Benjathat: five colors and shapes. }\end{array}$ \\
\hline
\end{tabular}

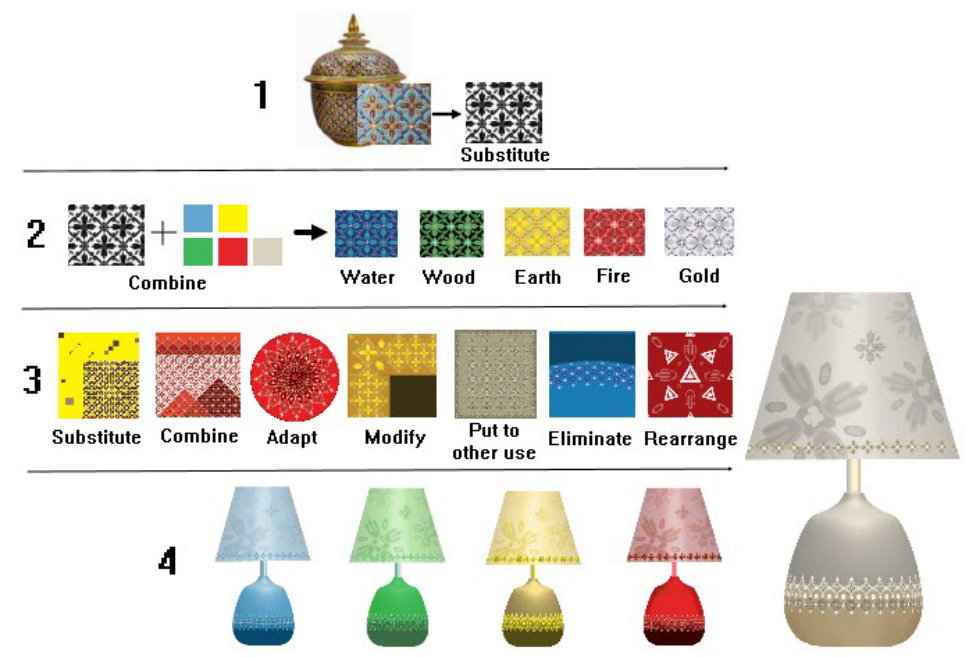

Figure 1. The application of SCAMPER to the cultural products in the bicultural context (source: created by author)

\section{Discussion}

Although colors are common in both cultures, they are different in context. Colors in the Benjarong play a role in creating a unique and beautiful design in the patterns. Presently, more than five colors are used in their original form. Those more distinctive colors, such as gold and silver, make Benjarong more attractive and valuable. Hence, the general public's perception may not perceive what the five colors of Benjarong consist of? Besides, the patterns appear to be significantly more prominent than the colors. But with Benjathat, colors represent elements and have a shared sense of consistency, such as green representing the wood element, yellow representing the earth element, red representing the fire element, white representing the gold element, and blue representing the water element. Therefore, the study asserted the colors of Benjarong and the pattern of Benjarong in integrating the bicultural context. 
The above case demonstrates how similar products/things in different cultures can be combined and communicated, fulfilling the proposed design thinking in level 3 . The further concern would be how designers elevate their thinking and move from level 1 to level 3. As the SCAMPER principle was applied to conduct design experiments, the results not only creativity in design, they can also represent the existence of level 1 through level 3 on account of the process that discussion on the SCAMPER principle applied to the design in a bicultural context. The first and second steps can express level 1 due to trivial changes in the original. The third step could present all of the levels on account of considerable ascending changes. And the fourth step is to apply the P to other use principle to reach the goals leading up to level 3.

Based on the discussion of the identify three levels of bicultural communication values, and due to the results of design experiments, it could be summarized correspondingly but in the other way, as level 1 is original, bringing traditional values showing up in design with trivial modifications or alterations. Level 2 is blending original that conveys the values that have existed in the original but modified and developed to create a new design while retaining the original values. Level 3 is being novelty adopting traditional values in the dimensions of wisdom, ideas, techniques, and processes to create new designs or new products. These three levels can be visualized in Figure 2.
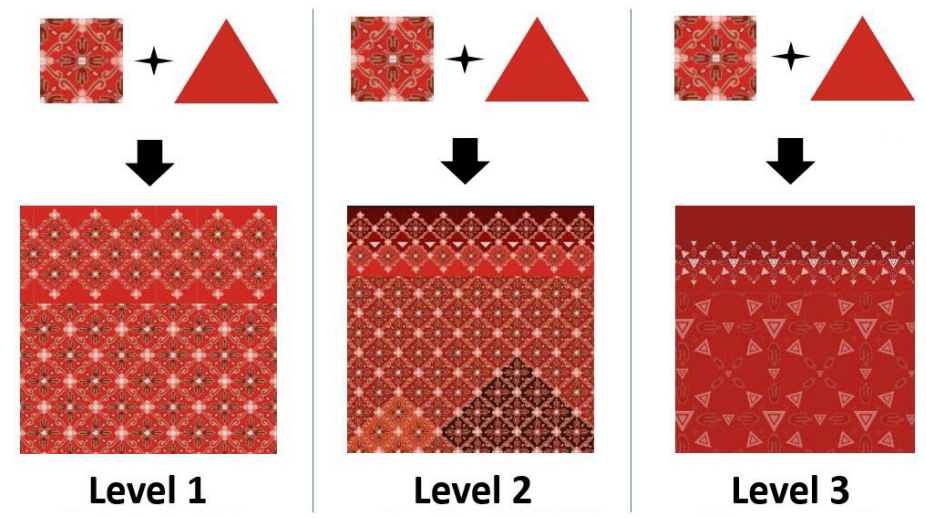

Figure 2. Visualization of levels 1-3 (source: created by author)

\section{Conclusions}

The study concluded bicultural communication values into three levels. The case study was presented to illustrate critical factors of bicultural thinking. These factors consist of knowledge exchange, inquiry learning. In the case of Benjarong and Benjathat, such factors assisted create new content and creative cultural products. Products purposed to fulfill in-depth communication must supply methods for knowledge and experience exchange. These products should not just present customers' prejudiced information; they should connect customers' authentic experiences to the external culture. Besides, designers should consistently have 
inquiries regarding how different cultures can communicate and generate various creative ideas. Finally, identifying the similarities and differences between two cultures is the transition to strategy in innovation. SCAMPER technic applied in this study is a helpful implement to create innovative cultural products. The study anticipates that the proposed case study could better comprehend innovative cultural product design in the bicultural context.

\section{References}

Albrecht, D., Lupton, E., \& Skov Holt, S. (2000). Design culture now: national design triennial. Laurence King Publishing.

Brown, T. (2009). Change by design: how design thinking transforms organizations and inspires innovation. HarperCollins Publishers.

Chaiyajan, T. (2013). Silpa Watanatham Ban Chiang nai Ngan Ookbaap Palitapanjaksan Prapet Khongthogthang Ban [Master's Thesis, Silpakorn University]. Bangkok, Thailand. https://so02.tcithaijo.org/index.php/fakku/article/view/29869/25715

Chen, Ch.-W. (2018). New product styles and concepts in the bicultural context. The Design Journal: An International Journal for All Aspects of Design, 21(6), 771-787. https://doi.org/10.1080/14606925.2018.1516496

Chiu, Ch., \& Kwan, L. Y.-Y. (2010). Culture and creativity: a process model. Management and Organization Review, 6(3), 447-461. https://doi.org/10.1111/j.1740-8784.2010.00194.x

Daly, Sh. R., Yilmaz, S., Christian, J. L., Seifert, C. M., \& Gonzalez, R. (2012). Design heuristics in engineering concept generation. Journal of Engineering Education, 101(4), 601-629. https://doi.org/10.1002/j.2168-9830.2012.tb01121.x

Eberle, B. (1996). SCAMPER: creative games and activities for imagination development. Prufrock Press Inc.

Evans, M. J., Moutinho, L., \& Raaij, van W. F. (1997). Applied consumer behaviour. Addison-Wesley Longman Ltd.

Friedman, R., \& Liu, W. (2009). Biculturalism in management: leveraging the benefits of intrapersonal diversity. In R. S. Wyer, Ch. Chiu, \& Y. Hong (Eds.), Understanding culture: theory, research, and application (pp. 343-360). Psychology Press.

Gaver, B., Dunne, T., \& Pacenti, E. (1999). Design: Cultural Probes. Interactions, 6(1), 21-29. https://doi.org/10.1145/291224.291235

Inkong, P. (2017). Kan Ookbaap Palitapan Wattanatham: Neawkid Rupbabb rae Khanvikraek. Unlimited Printing.

Julier, G. (2000). The culture of design. SAGE Publications.

Kaplan, M. (2004). Introduction: adding a cultural dimension to human factors. In M. Kaplan (Ed.), Advances in Human Performance and Cognitive Engineering Research: Vol. 4. Cultural ergonomics (xi-ix). E. Salas (Series Ed.). Emerald Group Publishing Limited. https://doi.org/10.1016/S1479-3601(03)04016-5

Lin, R.-T. (2007). Transforming Taiwan aboriginal cultural features into modern product design: A case study of a cross-cultural product design model. International Journal of Design, 1(2), 45-55.

Lockton, D. J. G. (2013). Design with intent: a design pattern toolkit for environmental and social behaviour change [PhD/Doctoral Thesis, Brunel University, London]. London, United Kingdom. https:// bura.brunel.ac.uk/handle/2438/7546

Mijares-Colmenares, B. E., Masten, W. G., \& Underwood, J. R. (1993). Effects of trait anxiety and the SCAMPER technique on creative thinking of intellectually gifted students. Psychological Reports, 72(3), 907-912. https://doi.org/10.2466/pr0.1993.72.3.907 
Moalosi, R., Popovic, V., Hudson, A., \& Lall Kumar, K. (2005, 1-4 November). Integration of culture within Botswana product design. In Proceedings of International Design Congress - IASDR 2005. International Design Congress - IASDR 2005. Yunlin County, Taiwan. https://eprints.qut.edu. au/2678/1/2678.pdf

Mok, A., \& Morris, M. W. (2010). Asian-Americans' creative styles in Asian and American situations: assimilative and contrastive responses as a function of bicultural identity integration. Management and Organization Review, 6(3), 371-390. https://doi.org/10.1111/j.1740-8784.2010.00190.x

Morris, R. (2016). The fundamentals of product design. Bloomsbury Publishing Plc.

Osborn, A. F. (1963). Applied imagination: principles and procedures of creative problem-solving. Charles Scribner's Sons.

Rodgers, P., \& Milton, A. (2011). Product design. Laurence King Publishing.

Schwartz, S. J., \& Unger, J. B. (2010). Biculturalism and context: what is biculturalism, and when is it adaptive? Commentary on Mistry and Wu. Human Development, 53(1), 26-32. https://doi.org/10.1159/000268137

Serrat, O. (2017). The SCAMPER technique. In Knowledge solutions: tools, methods, and approaches to drive organizational performance (pp. 311-314). Springer Open. https://doi.org/10.1007/978-981-10-0983-9_33

Shao, Y., Zhang, Ch., Zhou, J., Gu, T., \& Yuan, Y. (2019). How does culture shape creativity? A minireview. Frontiers in Psychology, 10. https://doi.org/10.3389/fpsyg.2019.01219

Schön, D. A. (1983). The reflective practitioner: how professionals think in action. Basic Books, Inc.

Whiteley, N. (1997). Design for society. Reaktion Books.

Zec, P. (2002). Lifestyle and product culture for a global age: good design. Innovation, 21(2), 34. 